\title{
Modelling for Benchmarking
}

Summary of group work edited by A.S. Carrie", P. Higgins" and P. Falster"

\section{ABSTRACT}

The main findings of the group discussion on modelling for benchmarking can be summarized as follows:

- benchmarking should be about comparing processes, not about enterprises, therefore identifying common processes is the key point,

- a business process serves a customer - who is willing to pay,

- IDEF0 was proposed as an analysis tool suitable for process modelling, however, many people present believed that IDEF0 does not provide enough capability. Other modified IDEF approaches may be suitable.

\section{SCOPE FOR DISCUSSION}

The briefing note for the groups work was provided in the following problem statement:

One definition of benchmarking (among numerous others) is:

"Benchmarking is the process of continuously comparing and measuring business processes against business leaders anywhere in the world to gain information that will help the organization take action to improve its performance"

As can be clearly seen from this definition, benchmarking focuses on business processes. The unit of analysis in benchmarking is the business process. To ease the task of choosing and documenting the processes to benchmark, a model of the company based on business processes should be available. Such a model should be a comprehensive framework, covering most of the generic processes contained in a general company.

\footnotetext{
") A.S. Carrie, Department of Design, Manufacture and Engineering Management, University of Strathclyde, James Weir Building, Montrose Street, Glasgow G1 1XJ, Great Britain.

“) P. Higgins, CIM Research Unit, University College Galway, Nun's Island, Galway, Rep. of Ireland

“.”) P. Falster, Electric Power Engineering Department, Technical University of Denmark, DK 2800 Lyngby, Denmark
} 
We will ask the group to discuss the feasibility of a such a framework, how to classify business processes, what processes should be represented in the framework, etc. Remember that the main task is to discuss modelling of the company for the purpose of benchmarking. The framework should be general enough to facilitate comparisons across companies and industries.

Based on the given problem statement above a very interesting open discussion took place and the remainder of this text attempts to synthesis this discussion.

\section{INTRODUCTION}

Modelling provides a basis for understanding, learning and development. The main task is to discuss modelling of a company for the purpose of benchmarking. It is said in the problem statement that such a model should be a comprehensive framework covering most of the generic processes. However, we would like to distinguish between a specific model for a specific company and a general model or framework covering as said most of the generic processes in a general company.

We prefer to use the term framework instead of model, because a framework does not require a theory in order to be used for design purpose. A framework may simply be a taxonomy or classification system.

We propose to use a Descriptive language, not necessarily a formal and executable language. For example IDEFO is a descriptive language.

The following items have to be discussed:

* clarifying our definitions

* framework

* research needs

* organization impact

How to compare two completely different companies, for example a pizza company and a ship yard? We should be able to dentify a common set of processes that could be compared for benchmarking and then perhaps supply rules that could be used to provide a scaling mechanism to allow different enterprises to be composed. The point is therefore to find the business processes to compare, instead of trying to compare "pizza's and ships". Benchmarking should thereby be about comparing business processes i.e. $P 3 A$ vs $P 3 B$ from enterprises $E A$ and EB, respectively (figure 1). In this figure two enterprises and a set of generic processes are illustrated.

Those processes, say $\mathrm{P} 3 \mathrm{~A}$ and $\mathrm{P} 3 \mathrm{~B}$, from the two enterprises which share the same generic processes should be compared. Thereby, this technique would facilitate comparisons across companies. Accordingly, we need criteria to identify comparable processes. Another question is also how should we develop a framework to describe individual processes rather than classify business processes. 


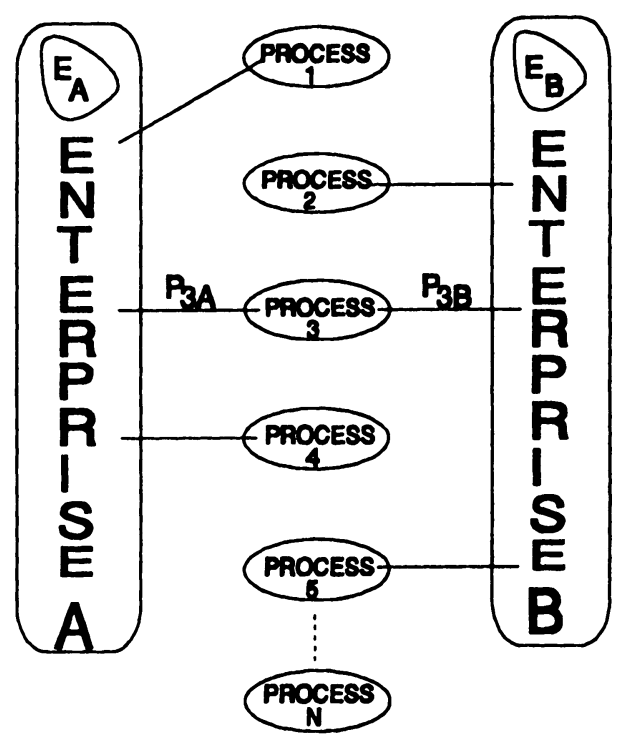

Figure 1. Relationships between Enterprises A and B and Business processes $1,2,3, \ldots ., n$.

The organizational structure of a company should not be important in the definition of generic processes, however, since one the objective of benchmarking and modelling is to change the organization to improve performance, a means of relating organization structure to process definition must be developed. This leads to questions such as How can the organization be modelled? For each business process, where are the organizational boundaries? How does the organization influence business processes?

\section{WHAT IS A BUSINESS PROCESS?}

What is a business process and how can we identify processes in the company? How do we define them? Is there any difficulty in defining them? Do we need to classify them? Does a process have certain definable characteristics? These are some of questions raised during the discussion.

Various definitions of business processes exist. Some of the definitions are found in the conference proceedings.

CIM-OSA [1]:

A Business Process is the business user's view of what tasks are required to achieve a particular enterprise objective. A task is a general term which includes Business Processes and enterprise activities. 
CIM-OSA's [1] three main categories of Business processes is Manage, Operate and Support (see also Childe \& Smart [7]):

Management processes (strategy planning, operations planning, performance monitoring and condition reporting) "Manage processes" as those which are concerned with strategy and direction setting as well as with business planning and control.

Operational processes (product development, manufacturing/product production) product marketing) "Operate processes" are viewed as those which are directly related to satisfying the requirements of the external customer, for example the logistics supply chain from order to delivery.

Support processes (installation, maintenance, set-up, repairing) "Support processes" typically act in support of the Manage and Operate processes. This include the financial, personnel, facilities management and Information Systems provision (IS) activities.

Burbidge's classification of industries using the material conversion classification system based on the ratio of material to product varieties (see this volume) is also a possibility to consider [5].

\section{REQUIREMENTS TO MODELLING TOOLS AND FEASIBILITY OF A FRAME- WORK}

Modelling the system should be in terms of 1) what the system is, 2) what is its environment and 3) the interaction between system and environment. Quality is the link between the system and its environment.

Several modelling methods were discussed. One view was that IDEFO was inadequate as a technique because it modelled functions or activities, not processes. Some participants had developed alternative techniques. Several approaches to developing software tools for business process re-engineering may be found in [13]. On the other hand it was agreed that IDEF0 could be used successfully provided a business process viewpoint was kept in mind. IDEF0 could then be used to:

- identify processes (activities)

- identify the environment in a hierarchical structure

The decisioned system approach and the Grai Grid as possible means of benchmarking information and decisioned flows should also be mentioned in this connection [14].

The discussion reflected inconsistency in the use of the terms, functions, activities and processes. An analogy to the discrete simulation field may be useful to clarify some of the problems.

It is well known that a modeler could either take a machine-oriented or activity-oriented view (as in CSL) or a material-oriented or process-oriented view (as in GPSS). For the 
Browne \& Bradley [3]:

A Business Process can be viewed as a set of logically related tasks performed to achieve a definite business outcome. These business processes have two important characteristics:

- They have customers, and

- they cross organizational boundaries

- are independent of formal organizational structure

Davenport \& Short [8]:

A Business Process is the logical organization of people, materials, energy, equipment and procedures into work activities designed to produce a specified end result.

Hickman [10]:

A Business process is a logical series of dependent activities which use the resources of the organization to create, or result in, an observable or measurable outcome, such as a product or service.

The definitions may seems different but they complement each other, where they do not overlap.

We can summarize the preceding definitions as follows:

A process is part of the value chain (according to Porter [12]). A Process is a sequence of operations or a series of steps. Could something that does not add value be a process? The answer is no.

There should be a customer because a process serves a customer, who is willing to pay. If it does not add value is it then a function? One person's function could be another's process (for example the personnel function). Let be added to the above definitions that there also should exist an External Event Trigger.

A process takes time and uses resources. It converts input to output. There are defined constraints, goals and objectives. Sample business processes include customer order entry, purchasing, product development, etc.

\section{HOW SHOULD BUSINESS PROCESSES BE CLASSIFIED, AND WHAT PROCESSES SHOULD BE REPRESENTED?}

There seems to be a variety of systems for classifying generic business processes. Burbidge defines an arterial flow system with nine generic functions: Design, Production planning, Production Control, Purchase, Market, Finance, Personnel, Secretarial and General management [4].

It was mentioned that for example Andersen Consulting defines 200 generic processes, IBM defines 17 generic processes, Childe \& Smart [7] defines 7 generic processes, Mertins [11] defines 183 generic processes and Champy [6] defines 5 generic processes. 
first viewpoint you place yourself on the machines or functions and watch the material input and output. For the second viewpoint you place yourself on the material, orders or information and watch the machines or functions you passes. The latter viewpoint is the dominant viewpoint as pointed out above for business process modelling.

However, it is also appreciated within simulation modelling that both viewpoint are equally useful depending of what you want to measure. This could explain the different viewpoints among the participants.

Analysis should be strictly goal-driven, modelling one level above the area of interest.

Required capabilities of modelling methods:

- hierarchical decomposition, defining the right granularity, level of detail,

- base level of primitive business processes in order to be able to compare similar procession different enterprises,

- reusability,

- transportability (to f.ex. EXPRESS),

- business processes are independent of how we implement them

- recursive or iterative,

- formalized structured methods,

- standardization,

- object-oriented,

The following dynamic business process model in figure 2 is proposed based on a descriptive model (not a formal or executable model):

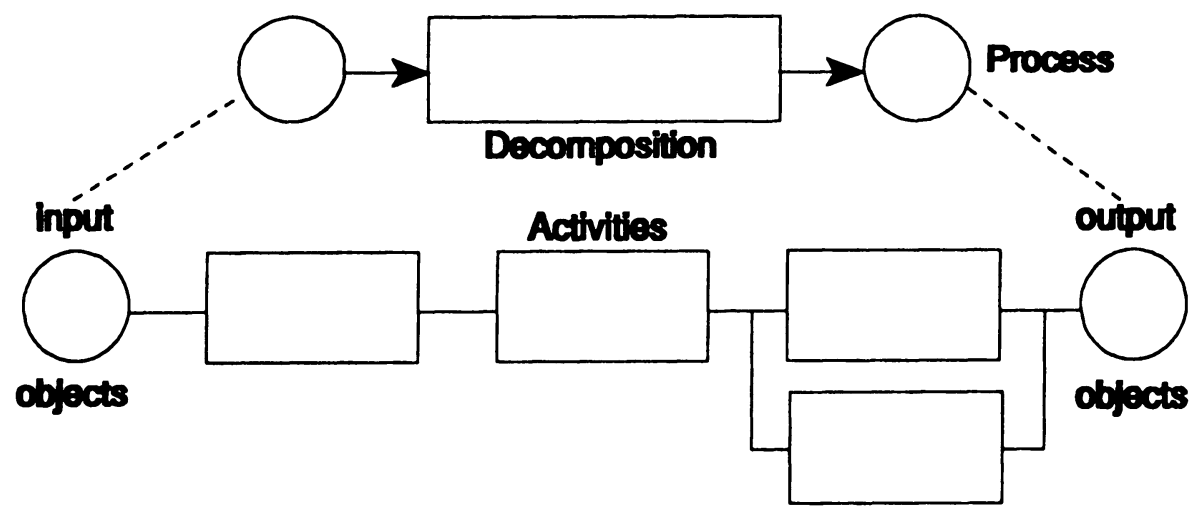

Figure 2. Dynamic Business Process Model.

The characteristics of a business model is summarized in figure 3. 


\begin{tabular}{|c|c|}
\hline \multicolumn{2}{|c|}{ A Business Process } \\
\hline Use & Resources \\
\hline Has & Customer \\
\hline Takes & Time \\
\hline Add & Value \\
\hline Triggered by & External event \\
\hline
\end{tabular}

Figure 3. Characteristics of a Business Process

\section{SUMMARY OF DISCUSSION AND OUTLOOK}

The existing organizational structure is not important in defining processes, but it is necessary to have a way for representing the organization, such that changes to improve the organization, can be described.

Some of the questions and answers discussed during the group work are summarized below:

Model of the company based on business processes, identify the processes.

Essential capabilities of and requirements for modelling methods include:

- hierarchical decomposition, defining the right granularity,

- base level of primitive business processes in order to be able to compare,

- reusability,

- transportability (to EXPRESS for example),

- business processes are independent of how they are implemented,

Nature of the environment.

Criterias to identify comparable processes:

- how to redesign the system in order to do comparison with the purpose of benchmarking,

Which tools are needed to do:

- performance comparison,

- feasibility study

Develop a framework to describe individual processes rather than classify business processes. 
Value-adding chain of business processes:

- have a customer to the business process,

Be strictly goal-driven, model one level above your interest.

Organization hierarchies is not of primary importance:

- for each business process, where are organizational boundaries?

- where does organization influence business processes.

Andersen consulting has developed 200 global standard business processes covering a variety of enterprises.

How can two completely different companies, f.ex. pizza company and a ship yard be comparable. Find the business processes to compare (not apples and pears).

\section{Acknowledgement}

The participants in the group discussion are thanked for their valuable contribution to this report.

\section{REFERENCES}

1. AMICE Vol1: Open System Architecture for CIM. ESPRIT Consortium AMICE (Eds.). Project 688, Springer-Verlag, 1989.

2. R.R. Bravoco \& S. B. Yadeav: Requirement Definition Architecture - An Overview. Computers in Industry 6 (1985), pp 237-251.

3. J.Browne \& P. Bradley: Business Process Reengineering (BRP) - A Study of the software tools currently available. Working paper at CIMMOD/CIMDEV meeting, Bordeaux, France May 9th \& 10th 1994. CIMRU, University College Galway.

4. J.L. Burbidge: Production Control: A Universal Conceptual Framework. Production Planning and Control., Vol. 1, No. 1, pp 1-13.

5. J.L. Burbidge: The "Material Conversion Classification". IFIP 5.7 Working Conference on Benchmarking - Theory and Practice, Trondheim, Norway, june 16-18, 1994, Chapman \& Hall (in this volume).

6. Champy, R.C.: Benchmarking - The Search for Industry best Practices that Lead to Superior Performance. ASQC Quality Press, Milwaukee, Wisconsin, 1989. 
7. S.J. Childe \& P.A. Smart: Benchmarking - An Approach Using Process Modelling for Redesign. IFIP 5.7 Working Conference on Benchmarking - Theory and Practice, Trondheim, Norway, june 16-18, 1994, Chapman \& Hall (in this volume).

8. T.H. Davenport \& J.E. Short: The new Industrial Engineering: Information Technology and Business Process Redesign, Sloan Management Review, summer, 1990.

9. M. Hammer \& J. Champy: Reengineering the Corporation: A Manifesto for Business Revolution. Harper Business, 1993.

10. L.J. Hickman: Technology and Business Process Re-engineering: Identifying Opportunities for Competitive Advantage, British Computer Society CASE Seminar on Business Process Engineering, London, 29 june 1993.

11. K. Mertins: Benchmarking Techniques. IFIP 5.7 Working Conference on Benchmarking - Theory and Practice, Trondheim, Norway, june 16-18, 1994, Chapman \& Hall (in this volume).

12. M. E. Porter: The Competitive Advantage of Nations. The Free Press. 1990.

13. K. Spurr, P. Layzell, L. Jennison, N. Richards (eds): Software Assistance for Business Re-engineering, J. Wiley, 1993.

14. G. Doumeingts: System Analysis Techniques. In Computer-Aided Production Management, A. Rolstadås (ed.): IFIP State-of-the-Art Report, Springer Verlag 1988. 